ARTIGOS

\title{
Os conhecimentos didáticos na formação de professores
}

Léia de Cássia Fernandes Hegeto

\begin{abstract}
RESUMO: Este artigo trata sobre os conhecimentos didáticos presentes na formação de professores a partir da análise de manuais de Didática Geral publicados nas últimas décadas. Na pesquisa optou-se pela seleção e análise de 9 manuais de Didática publicados nas décadas de 80, 90 e 2000, sendo esses manuais publicados um no início, no meio e no final de cada década. A pesquisa em manuais de Didática que tem como objetivo ensinar professores a ensinar, evidenciou a presença de temáticas clássicas e a inserção de novos temas na área da Didática. Os resultados evidenciaram uma possível convergência da Didática com outras áreas de conhecimento e uma possível dispersão dos temas e conhecimentos específicos da área da Didática. Os temas tratados no âmbito dos manuais de Didática Geral estão ora relacionados diretamente com o ensino e aprendizagem, ora relacionados diretamente com a formação de professores reflexivos e críticos considerando a relação com o currículo, inovação, tecnologia e diversidade.
\end{abstract}

PALAVRAS-CHAVE: Disciplina de Didática, Didática Geral. Formação de Professores

\section{The didactic knowledge in teachers' formation}

\begin{abstract}
This article deals with the didactic knowledge present in the formation of teachers from the analysis of General Didactics manuals published in the last decades. In the research the selection and analysis of 9 didactic manuals published in the 80's, 90's and 2000's were chosen, and these manuals were published one at the beginning, middle and end of each decade. The research in Didactics manuals that aims to teach teachers to teach, evidenced the presence of classic themes and the insertion of new themes in the area of Didactics. The results showed a possible convergence of didactics with other areas of knowledge and a possible dispersion of themes and specific knowledge in the Didactics area. The themes dealt with in the General Didactics manuals are directly related to teaching and learning, both directly related to the formation of reflective and critical teachers considering the relation with curriculum, innovation, technology and diversity.
\end{abstract}

KEY WORDS: Didactics Subject; General Didactics; Teachers' Formation. 


\section{autêntica}

DOI https://doi.org/10.31639/rbpfp.v\%vi\%i.189

\section{INTRODUÇÃO}

Parte-se do reconhecimento de que os conhecimentos didáticos se constituem como essenciais na formação docente e podem ser entendidos como aqueles conhecimentos mobilizados pelo professor no ato de ensinar. Podem ser considerados didáticos os conhecimentos relacionados ao processo de ensino, como por exemplo: a seleção de um conteúdo a ser ensinado; clareza dos objetivos; intencionalidade desse conteúdo; seleção de métodos e estratégias voltadas às necessidades de aprendizagens dos alunos; seleção de recursos e formas de avaliação adotadas em sala de aula.

Tais conhecimentos podem e devem ser trabalhados no âmbito das disciplinas de Didática Geral, Fundamentos da Educação, Currículo e Metodologias de Ensino.

No que se refere ao lugar que ocupa a disciplina de Didática nos cursos de formação docente, verifica-se que apesar do reconhecimento de sua importância, tem ao longo dos anos perdido o prestígio que obteve nas décadas anteriores. Para Mello (2002) a trajetória da disciplina de Didática passou por períodos de auge, queda e retomada. "A disciplina deixou de ser a "rainha" do currículo dos anos 80 e reinicia uma nova fase de valorização [...]" (MELLO, 2002, p. 18, grifos da autora).

No que se refere aos temas abordados nessa disciplina, Mello (2002) evidencia a preocupação em relacionar a Didática às necessidades de cada período e contexto histórico em que esta inserida. A disciplina Didática Geral tem um compromisso direto com o ato de ensinar e com os elementos que envolvem a ação docente de uma forma crítica e contextualizada. A escola como espaço de construção e reconstrução de conhecimentos, deve estar comprometida com um conhecimento escolar que atenda as necessidades de formação dos alunos.

Cabe a disciplina de Didática trabalhar os conhecimentos didáticos que serão mobilizados pelo professor durante a aula e esses, vão desde o planejamento inicial a definição de metodologias e forma de avaliação, perfazendo um ciclo contínuo de aprendizagens significativas aos alunos.

A Didática tem um compromisso com a reflexão crítica dos fundamentos da educação, como função social da escola e do professor, considerando as diferenças individuais de aprendizagem e a diversidade cultural, histórica e social dos alunos. De acordo com Mello $(2002$, p.17) a Didática esteve sempre "relacionada com um período e necessidades de um contexto histórico vivido e lutou todo esse período para assumir-se como uma disciplina necessária a uma escola de formação de professores".

Sabe-se que a Didática no Brasil surge como disciplina obrigatória no currículo dos cursos de formação de professores e licenciaturas. A disciplina que se constituiu no principal ramo de estudos da Pedagogia, investiga de acordo com Libâneo (2008) os fundamentos, as condições e os modos de realização da instrução e do ensino.

A pesquisa de que se trata esse artigo inserem-se, nos debates sobre a Didática Geral na formação de professores, considerando os manuais de Didática Geral como fontes importantes na análise das características da disciplina de Didática nas últimas três décadas. Na pesquisa parte-se do entendimento de que os manuais são livros que tem como objetivo específico ensinar a ensinar, tal como defende Silva (2008):

[...] os manuais para professores tiveram um conteúdo específico, ensinaram a ensinar, tratando de temas ligados ao desenvolvimento infantil, às técnicas de ensino, ao papel do professor, à organização da escola e das aulas, etc. Ou seja, se é verdade que tanto os manuais dos alunos quanto os dos professores podem ser considerados como produtos da cultura escolar, os livros das normalistas também dão a ver aspectos da constituição de um corpo de saberes profissionais docentes (SILVA, 2008, p. 117, grifos da autora). 


\section{autêntica}

DOI https://doi.org/10.31639/rbpfp.v\%vi\%i.189

A análise de manuais permite encontrar elementos que contribuam para entender características da disciplina Didática no período estudado. Parte-se da compreensão de que manuais de acordo com Cuesta Fernandez (1998) são 'elementos visíveis' e, portanto, expressões do código disciplinar da Didática Geral como disciplina escolar. A partir desse conceito, se admite que os conhecimentos contidos nesses manuais expressam e influenciam o ensino em determinada época, sugerindo regras e normas, legitimando conteúdos, ideais e discursos e que, ainda, manifestam relações com disciplinas e currículos dos cursos de formação de professores, seja na Pedagogia ou em outras licenciaturas.

Concorda-se com Chervel (1990), quando reitera que as disciplinas escolares podem assumir determinadas finalidades no ensino escolar, constituindo-se em verdadeiros dispositivos pedagógicos que se materializam por diferentes formas, dentre essas, os manuais, que revelam temáticas e conhecimentos didáticos na área da formação de professores.

Um dos objetivos dessa pesquisa foi verificar a relação que os professores estabelecem com as orientações didático-metodológicas, sugeridas nos manuais. Desse modo, buscou-se, a partir da análise dos conteúdos dos manuais de Didática Geral, perceber as orientações e conhecimentos didáticos ali contidos e se esses estiveram presentes nos espaços de formação de professores no país.

Destinados aos professores, esses manuais podem ser tomados como fontes empíricas para investigar a presença de elementos que, em dados períodos históricos, demarcaram as formas de pensar e de desenvolver o ensino no país (GARCIA, 2006). Quando se toma, por exemplo, as temáticas presentes nos manuais, é possível verificar qual tem sido os conhecimentos didáticos priorizados em cada momento e considerados necessários ao professor em formação.

\section{AS TEMÁTICAS CLÁSSICAS E AS TEMÁTICAS NOVAS TRABALHADAS NA DISCIPLINA DE DIDÁTICA GERAL}

Pesquisas como as de Veiga et al (2010), Libâneo (2010) Marin et al. (2012), Vieira e Martins (2009), Candau e Leite (2007), Martins e Romanowski (2010) têm apontado as possíveis lacunas e propostas para a disciplina de Didática enquanto um componente curricular balizador na orientação da prática pedagógica de futuros professores.

A discussão sobre o ensino no âmbito da disciplina, assim como a reflexão sobre os temas clássicos e temas novos e a tendência atual da formação de professores, se constitui como fundamental para o fortalecimento e reconhecimento da Didática como uma importante disciplina escolar. Apesar das inúmeras divergências, há, de acordo com Marin et al. (2012, p. 52), um consenso entre os pesquisadores e no âmbito dos manuais analisados na área pedagógica de que "cabe à Didática focalizar o ensino nas várias etapas da escolarização, buscando levar os estudantes à aprendizagem de tudo o que for possível de modo a bem formá-los".

A Didática tendo como núcleo o ensino assume a responsabilidade com diversas temáticas, inclusive, aquelas que relacionadas à área do Currículo. Apesar da sua identidade própria, o Currículo e a Didática são campos de conhecimento que se intersetam (PACHECO; OLIVEIRA, 2013).

O currículo está relacionado ao processo de ensino, pois envolve "os espaços/tempos em que os sujeitos interagem, as ações escolares e culturais que se desenvolvem e as renovadas tecnologias que são aí empregadas" (MOREIRA; MELGAÇO DA SILVA JÚNIOR, 2016, p.48). Verifica-se que muitos conhecimentos 


\section{autêntica}

DOI https://doi.org/10.31639/rbpfp.v\%vi\%i.189

trabalhados na disciplina de Currículo podem ser trabalhados na disciplina de Didática, no entanto, há temas e conhecimentos específicos da Didática da área da Didática, como por exemplo, o tema planejamento que geralmente não é trabalhado na disciplina de currículo.

Não se pode negar a relação entre as áreas do Currículo e a Didática. Castro (1991) a esse respeito destaca que o ensino, é objeto de controvérsias teóricas e também de disputa no campo interdisciplinar do "currículo", já que o conteúdo do ensino - o que se ensina - tanto pode ser problema didático quanto curricular. Verificase, que "o inter-relacionamento da Didática com outros campos de conhecimento é intenso e constante, o que de modo algum prejudica sua autonomia, mas, ao contrário, vem enriquecê-la" (CASTRO, 1991, p. 22).

A Didática tem tratado de diferentes conteúdos, que são influenciados por tendências doutrinárias ou teóricas de diversos campos de conhecimento. Verifica-se que diante da complexidade de questões que marcam o processo de ensino, algumas obras ou cursos tem privilegiado determinadas inflexões - sociológicas, psicológicas, filosóficas, interpretando o ensino de muitos modos (CASTRO, 1991, p. 21).

Essas pesquisas tem mostrada que há uma diversificação quanto às temáticas abordadas na disciplina, nas quais se destacaram as referências sobre os chamados temas clássicos da Didática evidenciados no campo de conhecimento, no âmbito da disciplina e enquanto temática dos manuais de Didática Geral, como será demonstrado no decorrer desse texto.

Os temas clássicos pode-se dizer que são aqueles temas relacionados aos elementos do ensino e seu processo como, por exemplo: ensino, aprendizagem, finalidades do ensino, objetivos, conteúdos, relação professor-aluno, metodologia, recursos de ensino, avaliação, etc. Convém destacar que há no campo de pesquisa diferentes entendimentos sobre quais seriam esses temas clássicos.

Esses temas são assim chamados por se constituírem em temáticas consideradas importantes na disciplina de Didática e nos cursos de formação de professores e por estarem presentes até o momento atual, principalmente nos manuais didáticos que têm como função ensinar professores a ensinar. Os temas clássicos são mencionados em pesquisas de autores como Pimenta (2008), Franco e Guarnieri (2011), Libâneo (2002), Veiga et al.(2010), Lacanallo et al. (2007).

Relacionados ao ensino e aprendizagem e à atuação do professor em sala de aula, os temas clássicos da Didática são selecionados pelo reconhecimento de sua contribuição na formação docente ou escolhidos em razão da força da tradição. Muitos desses temas foram, ao longo do período, citados nas Diretrizes Curriculares organizadas para cada nível da educação ou pelos Cursos de Formação de Professores, ementas e manuais didáticos.

A existência de conhecimentos didáticos clássicos está justificada na ideia de que são temas considerados essenciais ao professor em processo de formação. Considera-se que sem os tais temas voltados ao processo de ensinar, a formação desse docente ficaria incompleta para o enfrentamento do dia a dia escolar.

Uma questão importante relacionada aos temas trabalhados na disciplina de Didática nos cursos de formação de professores diz respeito à afirmação presente no estudo de Gatti e Nunes (2009) de que a formação atual dos docentes tem se dado algumas vezes de forma descontextualizada da escola, pois não tem trabalhado com os licenciandos, futuros professores, o que e o como ensinar. É apontado também por esses autores que "a escola, enquanto instituição social e de ensino, é elemento quase ausente nas ementas, o que leva a 


\section{autêntica}

DOI https://doi.org/10.31639/rbpfp.v\%vi\%i.189

pensar numa formação de caráter mais abstrato e pouco integrado ao contexto concreto onde o profissional-professor vai atuar" (GATTI; NUNES, 2009, p. 55).

A porcentagem de horas destinadas à disciplina de Didática, às metodologias específicas e disciplinas conexas $(28,2 \%)$ indica que a formação profissional específica é, na maior parte das instituições, pouco valorizada no conjunto do curso, além de predominarem nas ementas conteúdos bastante genéricos, com pouca densidade teórica (GATTI; NUNES, 2009). Situação essa que vem se somando ao distanciamento dos conteúdos e temáticas relacionadas ao processo e elementos de ensino, podendo caminhar a disciplina para uma descaracterização do ensino enquanto seu objeto.

Em relação a essa questão Libâneo $(2008$, p. 237) tem questionado o "Por que hoje os programas de didática tratam de todos os temas, menos daqueles que ajudam os professores a atuarem eficazmente nos processos de aprendizagem dos alunos?", indicando a necessidade de que sejam repensados os conhecimentos didáticos trabalhados na formação de professores.

Pode-se dizer que a introdução de temas novos não convencionais, parece indicar esforços de mudança ou inovação nos conteúdos da disciplina. A presença marcante de novas temáticas a partir da década de 1990 é visível no interior da disciplina de Didática, seja nas pesquisas ou nos manuais. A esse respeito, autores como Maia e Monteiro (2011, p. 9) têm defendido que a incorporação de enfoques teórico-metodológicos, tais como professor reflexivo, professor pesquisador, identidade docente, questões relativas ao cotidiano escolar, ganhou força e ainda continua a influenciar as práticas pedagógico-didáticas dos professores.

Não se pode negar a partir do que se tem destacado nas pesquisas e manuais, que as discussões na formação de professores nos últimos anos têm estado apoiadas na reflexão das práticas pedagógicas e no discurso de inovação e práticas inovadoras de ensino que incluam a diversidade e o uso de tecnologias e novas metodologias ativas em sala de aula. A ênfase nesses conhecimentos indica a tentativa de dar respostas às urgências demandadas pela própria prática. "Uma forte tendência na disciplina Didática é de se discutir com os futuros professores a prática docente, buscando instrumentalizá-los para a construção de uma nova prática" (PIMENTA, 2008, p. 25).

No entanto, apesar da presença de temas novos, verificou-se que os temas mais constantes abordados, de acordo com Libâneo (2010), são: planejamento de ensino, conteúdos e métodos, relação professor-aluno e avaliação, como se pode verificar nos exemplos abaixo:

-Conceito de Didática. - Estruturação do trabalho docente. - Planejamento educacional: objetivos e conteúdos de ensino, métodos, estratégias e técnicas de ensino. - Avaliação da aprendizagem. Fundamentos (filosóficos, históricos, sociológicos, psicológicos da Didática, epistemológicos). - A estruturação do trabalho docente. - Dinâmica da prática pedagógica. - Planejamento e elementos constitutivos: objetivos, conteúdos, estratégias/procedimentos, técnicas, recursos. - Avaliação. Relação professor-aluno (LIBÂNEO, 2010, p. 568).

Embora os resultados tenham demonstrado que haja uma variedade de temáticas nas ementas, é preciso alguns cuidados quando se trata de sua análise, pois sabe-se que as ementas podem constituir-se em fontes às vezes frágeis de pesquisa, uma vez que o fato de um determinado conteúdo constar na ementa pode, no entanto, não significar que tenha sido trabalhado. 


\section{autêntica}

DOI https://doi.org/10.31639/rbpfp.v\%vi\%i.189

Por outro lado, arrisca-se a alegar que a disciplina de Didática, juntamente com as disciplinas de Fundamentos da Educação, Estágio e Prática de Ensino, é uma das disciplinas mais importantes no currículo de acordo com alunos, como pode ser verificado em pesquisas que utilizam entrevistas com alunos em formação.

\section{OS CONHECIMENTOS DIDÁTICOS PRESENTES NA DISCIPLINA DE DIDÁTICA GERAL NOS CURSOS DE PEDAGOGIA E LICENCIATURAS}

Percebem-se quanto aos conhecimentos didáticos presentes no currículo dos cursos de licenciatura uma estreita relação entre o campo da Didática, do Currículo e da Pedagogia. Tanto a Didática como a Pedagogia como teoria, campo investigativo ou atividade prática está, de acordo com Pimenta, Franco (2010, p. 831), "longe de obter uma posição de consenso sobre seu significado, dificultando sobremaneira a definição do que seria a essência do proceder pedagógico".

Muito se tem debatido nas pesquisas sobre a natureza e o objeto da pedagogia (PIMENTA, FRANCO, 2010; FRANCO; FUSARI, 2010) e de seu campo teórico e profissional (LIBÂNEO, 2010). Desse modo, considera-se como conhecimentos essenciais no proceder pedagógico de acordo com Pimenta, Franco (2010), a análise crítica e contextualizada da educação e do ensino "enquanto práxis social, formando o profissional pedagogo com formação teórica, científica, ética e técnica para atuar no estudo da teoria pedagógica, na pesquisa educacional e no exercício de atividades pedagógicas específicas" (PIMENTA, FRANCO, 2010, p. 848).

A tentativa de revelar o que constitui campo da Didática e o que constitui campo da pedagogia e a presença da ideia da Pedagogia como sendo a teoria e a prática da educação, e a Didática, o campo da Pedagogia que trata do ensino, marcou a trajetória da Didática tanto quanto campo de conhecimento quanto como disciplina escolar. Isso, pois, alega-se, tal como Franco e Fusari (2010, p. 75), que "a distinção conceitual e prática entre Didática e Pedagogia não é fácil, nem acredito que seja uma questão resolvida".

Não se tem a intenção de entrar na discussão sobre a distinção e divergência de perspectiva entre Pedagogia e Didática, tanto pela proximidade quanto distancia entre os conhecimentos e objetos de investigação específicos dessas áreas.

No ensino de Didática, defende-se a posição de que mais do que ensinar técnicas de planejar, orientar e avaliar a aprendizagem, tendo por base modelos ou princípios importados de outras áreas de saber, ou construídos no interior da teoria Didática, a disciplina deve propiciar a análise crítica da realidade do ensino por parte dos professores-alunos, buscando problematizá-la e explicá-la à luz do contexto em que se produz; dessa problematização, devem se buscar respostas ou novas perguntas às questões postas, para o que se recorre ao universo das sistematizações teóricas na área (ANDRÉ; OLIVEIRA, 1997, p. 14).

Verifica-se que muitos são os conhecimentos que fazem parte do universo complexo que é o campo pedagógico. O que leva muitos professores, de acordo com Marin et al. (2012) a acabar abordando conteúdos de outros campos de conhecimento por trazerem contribuições à formação do professor, ocasionando ao discurso didático atual, uma desorientação quanto as suas prioridades e temáticas:

Aparentemente, os professores de Didática confundem ao pensar em abordar conteúdos de outras áreas de conhecimentos, que trazem contribuições para a compreensão para a formação do professor sobre o ensino, os quais precisam ser considerados no momento de ensinar, porém não podem ser confundidos com os específicos da Didática. Assim, conhecimentos sobre as condições sociais 


\title{
autêntica
}

DOI https://doi.org/10.31639/rbpfp.v\%vi\%i.189

\begin{abstract}
dos alunos, seu desenvolvimento e condições para a aprendizagem, condições materiais sobre o trabalho de ensinar, formas de organização das escolas e de seus planos e as consequências para o ensino, finalidades educativas relativas a valores a nortear toda a formação do alunado, são alguns conhecimentos de toda a complexa área pedagógica. [...] Porém, não substituem os que compõem a Didática, que, ao lado deles, complementam a formação dos estudantes para o exercício de sua função (MARIN et al., 2012, p. 67).
\end{abstract}

Quanto aos conhecimentos didáticos que poderiam contribuir, de acordo com Marin et al. (2012), com a prática em sala de aula, esses autores sugerem que sejam abordadas, sobretudo, questões internas à sala de aula, como: as exigências de cada aula com seus conteúdos; seus diversificados procedimentos; recursos materiais; o planejamento de tarefas e sequências de atividades; seu lugar no projeto político-pedagógico global da escola; as formas de relacionamento com os alunos e entre eles; as formas de avaliação e relações com a organização do trabalho pedagógico da escola nos diferentes ambientes.

Os temas chamados clássicos na Didática sofreram a partir da década de 70 críticas e uma possível negação quanto a seu caráter técnico e prescritivo, evidenciando a necessidade de se pensar a prática pedagógica como prática social (CRUZ, ANDRÉ, 2014). Esse momento marcou a tentativa de superação de uma Didática exclusivamente instrumental pela construção de uma Didática fundamental proposta por Candau (1983).

No entanto, apesar das críticas sofridas, os temas continuaram a serem abordados ao longo do período nas pesquisas e na trajetória dos manuais de Didática Geral e, com maior ou menor ênfase, esses conteúdos não deixaram de existir nessa disciplina nos cursos de formação de professores. Após serem acusados de tecnicismo, esses temas retomam no meio educacional, pois cabe, de acordo com Marin et al. (2012, p. 72), "mantê-los por serem de fato centrais, porém operar com eles de forma descritiva, analítica, crítica". Esses autores acrescentam ainda, que não cabem prescrições, mas sim compreensões sobre esses conteúdos, de modo a estabelecer relações com os demais conhecimentos pedagógicos. Para esses autores é preciso retomar o papel central conferido à Didática, qual seja: [...] interessa à área de Didática voltar-se a algo que Ihe é peculiar - como o modo de agir para ensinar [...] (MARIN, 2008, p. 10).

No manual Ensinar a Ensinar: Didática para a escola Fundamental e Média de Castro e Carvalho (2001, p. 15) a ação de ensinar é descrita como: " [...] uma intenção e indica que na maior parte das vezes há um longo caminho entre o propósito e sua realização. Para tanto, entram em cena procedimentos ditos didáticos, que objetivem o ensinar e o aprender." Percebe-se que os conceitos e funções atribuídos à Didática, independente da concepção e ideia pedagógica, têm buscado responder as demandas da escola de seu tempo. Pode-se ainda mencionar as discussões em torno da relação teoria e prática e a dimensão que essa última tem assumido nas pesquisas e no âmbito de alguns manuais didáticos de um modo geral.

Na trajetória da disciplina de Didática, a discussão sobre a relação teoria-prática foi assumida nas pesquisas do campo e no âmbito de alguns manuais didáticos publicados a partir da década de 1990. Nesse sentido, houve a busca pela integração das disciplinas de prática de ensino e estágio e a tentativa de minimizar a dicotomia teoria-prática existente a partir do contato direto dos alunos com a prática. "Nessa concepção a teoria não é entendida como verdade que vai guiar a prática, mas como expressão de uma relação, de uma ação sobre a realidade, que pode indicar caminhos para novas práticas, nunca guiá-la" (MARTINS, 2008, p. 595).

O enfrentamento da questão epistemológica da disciplina permite compreender as relações entre o conteúdo proposto na disciplina e as práticas de sala de aula. Focada naquilo que se constituía em uma grande 


\section{autêntica}

DOI https://doi.org/10.31639/rbpfp.v\%vi\%i.189

preocupação nas pesquisas sobre o campo, André (2008) tem buscado saber "o que e como se ensina na disciplina de Didática, para compreender como ela vem se constituindo no curso de formação de professores e no que respeitam aos conteúdos abordados quais têm sido as contribuições reveladas no cotidiano escolar" (ANDRÉ, 2008, p. 499).

Para André (2000), essa tendência de "trazer as questões do dia a dia da escola para serem examinadas pelos alunos-professores favorece a articulação teoria e prática" (ANDRÉ, 2000, p. 203) e tem possibilitado que as questões Didáticas sejam analisadas dentro de um contexto escolar específico. Os conhecimentos didáticos são marcados por um processo metodológico de reflexão sobre a própria prática, entendendo que o saber da prática deve ser tomado como ponto de partida para a recriação da prática docente.

Autores como Veiga et al (2010) apontam o espaço da aula enquanto um lócus de formação de professores privilegiado para a reflexão do processo didático e construção do conhecimento. A obra de Veiga et al (2010), que tem como objetivo discutir os elementos constitutivos da aula e suas relações mostram que a aula é entendida como algo que vai além da organização do espaço físico e que define o papel do professor, do estudante, do conhecimento e dos procedimentos e recursos didáticos, tendo como finalidade "promover a educação formal do cidadão, envolvendo suas práticas e relações entre agentes do processo educativo, cujo objetivo principal é o ensino e a aprendizagem" (VEIGA et al, 2010, p. 49).

André e Cruz (2012) advertem quanto à importância da formação de professores envolver, dentre outras questões, "o estudo da prática por meio da investigação oral, baseando-se em conversas profundas a respeito: do trabalho de ensinar e aprender; observações e reflexões, feitas por professores, na sala de aula [...]" (ANDRÉ; CRUZ, 2012, p. 85).

A preocupação, portanto, nesse texto foi mostrar quais têm sido os objetos de preocupação da Didática nesses últimos anos na tentativa de revelar elementos que caracterizem o seu código disciplinar. A análise das pesquisas produzidas no campo foi fundamental no entendimento e na contextualização das principais discussões que marcaram a trajetória da Didática, como também revelar a ênfase dada pelos autores as temáticas relacionadas aos elementos de ensino e aos conhecimentos considerados necessários à formação do professor em cada período.

Diante da diversidade de temáticas que podem ser tratadas no âmbito da Didática, se reconhece nessa pesquisa a impossibilidade de esgotar as questões apresentadas. Nesse sentido, é necessário retomar que o objetivo aqui pretendido foi indicar elementos que permitem compreender a trajetória da disciplina de Didática como disciplina escolar e campo de conhecimento e apresentar elementos que ajudem na discussão dos conhecimentos didáticos trabalhados nos cursos de formação de professores.

\section{A PESQUISA: O QUE REVELAM OS MANUAIS DE DIDÁTICA GERAL PUBLICADOS A PARTIR DE 1980 ?}

Os manuais podem ser tomados como elementos que contribuem para a compreensão da trajetória da constituição das disciplinas escolares, entendidos na perspectiva de Chervel (1990) e Cuesta Fernandez (1998). O papel da disciplina na instituição de ensino é amplo, uma vez que se organiza a partir de conteúdos harmonizados e finalidades e resultados de aprendizagem já previstos e esperados (CHERVEL, 1990). A esse respeito o autor propõe que o ensino escolar da disciplina põe em ação as finalidades impostas à escola, podendo essas disciplinas tornar-se imperativas à medida que assumem finalidades sociopolíticas, 


\section{autêntica}

DOI https://doi.org/10.31639/rbpfp.v\%vi\%i.189

religiosas e educativas. Isso leva a pensar que a instituição escolar combina finalidades que a sintetizam como espaço de função educativa e de ensino e as disciplinas escolares estão no centro desse dispositivo.

Tomando como pressuposto essa ideia, pode-se afirmar que os manuais têm contribuído, a partir de sua organização e dos conteúdos que veiculam, tanto para uma estabilidade quanto para uma abrangência da disciplina, tal como foi defendido por Chervel (1990). Tais materiais podem ser considerados como agentes de renovação das disciplinas, pois a "estabilidade de uma disciplina resulta dos sucessos alcançados na formação dos alunos, assim como da sua eficácia na execução das finalidades impostas, processo esse que tem contado, sobretudo, com manuais adequados e renovados" (CHERVEL, 1990, p. 198).

Deve-se considerar que os objetivos das disciplinas evoluem e mudam tal como os conhecimentos e conteúdos de ensino tem se transformado. As mudanças que ocorrem no ensino em cada período no que se referem as suas finalidades e objetivos ocorrem impulsionadas "pela transformação social e cultural dos públicos escolares, dos seus alunos, o que é mais que suficiente para explicar essa evolução" (CHERVEL, 1990, p. 199).

Desse modo, os manuais podem assumir a responsabilidade com a formação de professor desejada no âmbito das disciplinas escolares em cada período. Pode-se pensar que há nos manuais uma intencionalidade tendo em vista, os conhecimentos didáticos e práticas ali difundidos. As ideias defendidas na disciplina e nos manuais de Didática Geral concebidos para a formação inicial de professores constituíram-se como os modos de ensinar esperados em cada período tornando-se como dispositivos de produção da identidade e representação do professorado em geral.

A análise de manuais didáticos teve como objetivo compreender elementos constitutivos da Didática como disciplina escolar, no período de 1980 a 2013, a partir do que se expressa nos manuais de Didática Geral, publicados a partir de 1980 no Brasil. Esses manuais são tomados como elementos que contribuem para a compreensão da trajetória de constituição de uma dada disciplina escolar, na perspectiva do código disciplinar (CUESTA FERNANDEZ, 1998).

Há dois elementos constitutivos do código disciplinar que são os elementos visíveis e os invisíveis (CUESTA FERNANDEZ, 1990). Dentre os elementos invisíveis estão as práticas que ocorrem no interior das salas de aulas e que podem revelar aspectos importantes sobre as disciplinas escolares. Como elementos visíveis do código disciplinar estão os manuais escolares, as ementas e programas, a legislação, as diretrizes curriculares, as normativas que definem e expressam finalidades, conteúdos e métodos que devem ser ou são utilizados no ensino e na formação de professores em cada período.

Ao partir desse reconhecimento iniciou-se a pesquisa em sites como Google e em bibliotecas virtuais e físicas a fim de verificar os livros e artigos em circulação com o título Didática Geral. A pesquisa em diferentes fontes permitiu que fosse obtido um conjunto de livros e artigos sobre Didática que, examinados em seu conteúdo, foram classificados nas seguintes categorias:

a) Manuais de Didática, que têm explicitamente a função de orientar as atividades de ensino, ou ensinar a ensinar.

b) Livros sobre Didática que, embora possam ser usados na formação de professores, destinam-se explicitamente a veicular a produção realizada no âmbito do campo de conhecimento.

c) Artigos que tratam do papel da Didática e sobre seu campo de pesquisa, 


\section{autêntica}

DOI https://doi.org/10.31639/rbpfp.v\%vi\%i.189

d) Artigos que tratam da Disciplina de Didática e seu ensino.

e) Artigos que tratam de Manuais de Didática Geral e de Didática Específica.

Diante da grande quantidade de fontes localizadas, foram selecionados 18 livros publicados a partir de 1980 que tinham como finalidade específica ensinar o professor a ensinar, chamados na pesquisa de manuais de Didática Geral. Dos 18 títulos localizados, optou-se em analisar três manuais de cada década, ou seja, um publicado no início da década, um no meio e o outro no final das décadas de 80, 90 e 2000. Essa opção foi feita pelo interesse em observar, nos manuais, as transformações ocorridas ao longo dessas três últimas décadas.

As nove obras selecionadas estão listadas no Quadro 1, a seguir:

QUADRO 1- MANUAIS DE DIDÁTICA SELECIONADOS PARA A ANÁLISE

\begin{tabular}{|c|c|c|c|c|}
\hline MANUAL 1 & Didática Geral & Claudino Piletti & 1982 & Ática \\
\hline MANUAL 2 & $\begin{array}{l}\text { Didática Geral: Fundamentos, } \\
\text { Planej., Metodol. e Avaliação }\end{array}$ & José do Prado Martins & 1985 & Atlas \\
\hline MANUAL 3 & $\begin{array}{c}\text { Didática teórica, Didática pratica: } \\
\text { para além do confronto }\end{array}$ & Pura Lucia O. Martins & 1989 & Loyola \\
\hline MANUAL 4 & Didática & Jose Libâneo & 1992 & Cortez \\
\hline MANUAL 5 & Curso de Didática Geral & Regina Célia C. Haydt & 1994 & $\begin{array}{c}\text { Ática } \\
\text { Didático }\end{array}$ \\
\hline MANUAL 6 & $\begin{array}{l}\text { Didática Geral um olhar para o } \\
\text { futuro }\end{array}$ & Maria Raineldes Tosi & 1996 & Alínea \\
\hline MANUAL 7 & $\begin{array}{c}\text { Ensinar a Ensinar- Didática para a } \\
\text { escola Fundamental e Média }\end{array}$ & $\begin{array}{l}\text { Amélia D. de Castro/ Ana } \\
\text { Maria P Carvalho (Orgs.) }\end{array}$ & 2001 & $\begin{array}{l}\text { Thompson } \\
\text { Pioneira }\end{array}$ \\
\hline MANUAL 8 & Lições de Didática & $\begin{array}{c}\text { IIma Passos A. Veiga } \\
\text { (Org.) }\end{array}$ & 2006 & Papirus \\
\hline MANUAL 9 & $\begin{array}{c}\text { Didática e docência: aprendendo } \\
\text { a profissão }\end{array}$ & $\begin{array}{l}\text { Isabel Maria S. de Farias } \\
\text { (Org.) }\end{array}$ & 2009 & Liber Livros \\
\hline
\end{tabular}

FONTE: Pesquisa da autora (2013)

Para o exame do material empírico, tomou-se a análise de conteúdo, na abordagem apresentada por Franco (2005) e Bardin (2009), não como método, mas como procedimento para analisar os conhecimentos difundidos nesses manuais. Foi a partir da leitura flutuante que surgiram dúvidas, interesses, lacunas, possibilidades de análise, constituindo-se como o momento de formulação de hipóteses de trabalho e definição das categorias 


\section{autêntica}

DOI https://doi.org/10.31639/rbpfp.v\%vi\%i.189

de análise. Não foi privilegiado, nesta pesquisa, o uso dos manuais pelos professores, mas sim o conteúdo dos enunciados contidos nesses manuais.

As categorias que estruturaram a análise dos manuais selecionados tiveram como objetivo destacar os elementos constituintes da disciplina de Didática no período entre 1980 e 2013. Elas correspondem aos elementos que, do ponto de vista das teorias adotadas, são estruturantes de uma disciplina escolar:

a) O conceito de Didática apresentado explícita ou implicitamente nos manuais.

b) As temáticas abordadas nos manuais, que compõem um corpo de conhecimentos didáticos considerados relevantes para serem ensinados no âmbito daquela disciplina específica;

c) As atividades propostas para orientar a aprendizagem dos alunos. Além do conhecimento a ser apresentado - seja pelo professor, seja pelos manuais.

Interessa aqui, apresentar os conhecimentos didáticos veiculados com o objetivo de revelar quais têm sido as temáticas apresentadas nos manuais nas últimas três décadas, tanto no que se referem às temáticas clássicas quanto as temáticas novas, que têm sido incluídas por diversas influências oriundas das orientações curriculares, da legislação e do campo científico da Didática, que respondem a novas demandas sociais.

No manual 9 - Didática e docência: aprendendo a profissão, organizado por Isabel Maria S. de Farias, entende-se a Didática como uma disciplina "que articula teoria e prática, escola e sociedade, conteúdo e forma, técnica e política, ensino e pesquisa; uma Didática que concebe os professores como sujeitos que aprendem uma profissão e se fazem profissionais na medida em que aprendem ensinando" FARIAS et al., 2009, p. 17).

Verifica-se nesse manual a perspectiva de romper com o ensino tradicional e recusar o aspecto meramente instrumental da Didática, que se expressa claramente no trecho abaixo:

Entendemos ser necessário romper com a concepção tecnicista de aprendizagem que ainda sustenta nossas práticas de ensino. É preciso pautar nossa atividade docente na compreensão da aprendizagem como um ato coletivo e contínuo, ir além da ação metodológica restrita à exposição verbal e aos exercícios de fixação (FARIAS et al., 2009, p. 124).

Optou-se pela análise das temáticas, pois parte-se da premissa de que os temas apresentados nos manuais remetem aos temas da disciplina de Didática e, portanto o que se espera enquanto conhecimentos didáticos necessários a formação docente. Verificou-se nos manuais analisados a presença predominante das temáticas clássicas da disciplina, ou seja, de temáticas relacionadas à ação Didática no processo de ensino.

No manual 9 - Didática e Docência aprendendo a profissão, verificou-se os seguintes temas: Educação, Pedagogia e Didática, Fundamentos da prática docente; Organização do processo didático: Planejamento e PPP; Métodos e Estratégias de Ensino; A aula como espaço tempo coletivo de formulação de saberes (objetivos); Avaliação e conteúdos de ensino.

Um exemplo de tema clássico da Didática é o planejamento. Percebe-se que o tema planejamento passou por uma ressignificação a partir da década de 1990, principalmente a partir das novas discussões sobre o papel do currículo e do Projeto Político Pedagógico na escola. Revela-se, uma ênfase na década de 2000 nas discussões sobre o projeto pedagógico na escola e nas discussões sobre currículo que, de acordo com esses manuais analisados, deve ser flexível, reflexivo e construído coletivamente. 


\section{autêntica}

DOI https://doi.org/10.31639/rbpfp.v\%vi\%i.189

Não se pode negar que o planejamento enquanto uma temática clássica e tradicional nos cursos de formação de professores se constitui em um elemento norteador que orienta e organiza o trabalho do professor na ação de ensinar. Planejar o trabalho em sala de aula contribui primeiramente para o entendimento do professor quanto à sua ação e a intencionalidade da disciplina e dos conhecimentos e práticas em sala de aula aprendidos e vivenciados. A partir do planejamento o professor poderá organizar a sua prática, selecionando os conteúdos e atribuindo-Ihes significados, propondo um encaminhamento didático e selecionando os recursos e avaliação que responda as necessidades dos alunos e da turma em que irá atuar.

Já em relação às novas temáticas presente nos manuais analisados foi evidenciado que a partir do final da década de 1980, foram incluídos alguns temas novos, como por exemplo, Identidade e fazer docente: aprendendo a ser e a estar na profissão; Educação, humanização e produção de identidades; A identidade profissional; Elementos identitários da docência - História de vida, formação e prática pedagógica; Saberes docentes (Manual 9).

Dentre os novos temas apontados nos 18 manuais de Didática localizados podem ser citadas, a partir de uma análise preliminar nos sumários, temáticas como: - competências; - professor reflexivo; - emancipação; - cultura escolar; - identidade do professor; representação social; - saberes escolares; - temas transversais; sistematização coletiva do conhecimento; - tecnologia; - informática; - sociedade digital; - multiculturalidade; - interdisciplinaridade; - pesquisa escolar; - ética; - estética; - diálogo; - prática social; - transposição Didática; - fracasso escolar; - disciplina/indisciplina; - educação inclusiva; - sexualidade; questões de gênero e raça, livro didático; - tempos-espaços; - dinâmica; - interação; - criatividade, - jogos; - dramatização; - recursos audiovisuais; - contradição social; - totalidade.

Esses diferentes temas indicam a tentativa de discutir e tratar as inúmeras situações presentes no dia a dia de sala de aula e que interferem no processo de ensino-aprendizagem. Além da necessidade de refletir os condicionantes e elementos que precisam ser considerados no ato de ensinar.

Das temáticas acima mencionadas, algumas apareceram em vários manuais, como, por exemplo, as temáticas do professor reflexivo, dos saberes escolares e da disciplina escolar. Cumpre ressaltar que a discussão em torno dos saberes necessários à docência destacou-se no âmbito das pesquisas de Didática, a partir de autores como Tardif (2002), influenciando certamente os autores que produziram e produzem manuais para o ensino da Didática.

Verificou-se que discussão da temática Aprendizagem e a temática ensino é uma preocupação da Didática Geral. Esses temas assumiram importância e lugar de destaque nas últimas três décadas. De um modo geral, os nove manuais analisados revelaram uma preocupação em apresentar orientações e discussões quanto aos modos de aprendizagem. Uma característica que os difere é que nos manuais publicados nas décadas de 1980 e 1990 a ênfase nos processos e discussões sobre a aprendizagem é maior e na década de 2000 a ênfase é menor. Isso, pela preocupação nesse momento em estar mais voltada ao ensino.

É evidente nos manuais a preocupação com a aprendizagem e com os resultados do ensino, incluindo aí as dificuldades em sala de aula, diferentes formas de interação, uso dos métodos e sistemas de avaliação, estão presentes nos nove manuais analisados, com abordagens e ênfases diferenciadas, mas sempre visando à melhoria do ensino e o desenvolvimento do aluno. 


\section{autêntica}

DOI https://doi.org/10.31639/rbpfp.v\%vi\%i.189

O resultado das análises permite anunciar que os manuais de Didática analisados têm, nesses últimos anos, se preocupado com o modo como ocorre a construção do conhecimento pelo aluno. A discussão sobre quais deverão ser os conteúdos, as metodologias, as formas de interação professor-aluno e os processos de avaliação tem como objetivo a formação e o desenvolvimento do aluno, conforme preconizado nos documentos legais no âmbito educacional brasileiro, que influenciam diretamente os rumos da educação e os próprios manuais.

Nos manuais analisados não há uma unanimidade quanto à abordagem e à forma de interpretar a aprendizagem. Há um grupo de manuais que alega a aprendizagem a partir do construtivismo e trabalhos de Piaget e que ressaltam a importância do papel ativo do aluno na aprendizagem; outro grupo de manuais ressalta e defende um ensino crítico que, enquanto um ato político, deve desenvolver no aluno a capacidade de reflexão visando sua autonomia e emancipação.

No manual 9, publicado em 2009, se verifica uma defesa explícita da pedagogia histórico-crítica, da perspectiva sócio-interacionista e da abordagem sócio-cultural de Vygotsky. Concebe-se a educação como ato político que tem suas ações voltadas para emancipação dos homens e transformação da sociedade.

O objetivo, ao mostrar as diferentes temáticas e conhecimentos didáticos presente nos manuais de Didática analisados, é revelar que, ao longo dessas três ultimas décadas, os manuais didáticos e a própria disciplina de Didática, mantêm a discussão sobre os processos de ensino-aprendizagem, embora apresentem novas temáticas com abordagens e enfoques diferenciados.

Para além de temas clássicos relacionados ao ensino, sua organização e seu desenvolvimento e suas relações com a aprendizagem dos alunos, os manuais apresentaram temas novos, que respondem a demandas novas no campo educativo, seja em decorrência das normas legais que foram produzidas nas duas últimas décadas, em especial após 1996, mas também para responder a debates no campo científico e a novas solicitações sociais - como a introdução da informática e tecnologias no ensino, as discussões sobre diversidade e relações étnico-raciais, de gênero e o enfrentamento dos preconceitos, entre outros. O que evidencia a preocupação da Didática Geral com a complexidade de questões que envolvem o processo de ensino. 


\section{autêntica}

DOI https://doi.org/10.31639/rbpfp.v\%vi\%i.189

\section{CONSIDERAÇÕES FINAIS}

Para além da necessidade de ressignificação da Didática como disciplina escolar, percebeu-se na pesquisa a relação próxima da Didática com outros campos de conhecimento e a consequente inclusão de novas temáticas que tem se constituído como novos conhecimentos didáticos. O que não significa necessariamente um problema, como tem sido apontado por alguns autores. Para André e Cruz (2013, p. 185), no que se refere à interdisciplinaridade e à articulação de saberes, "a diversificação não resulta em dispersão, mas em fonte catalizadora de circularidade de conhecimentos e práticas favorecedores à formação no ensino superior".

No entanto, não se pode deixar de reconhecer também que, do mesmo modo que há convergências, há também divergências entre os campos que podem levar a um distanciamento da Didática com relação aos conhecimentos que constituem sua especificidade. Segundo a pesquisa seriam os elementos constitutivos do ensino, ou seja, sabe-se que quando a disciplina de Didática deixa de cumprir o seu papel, que é proporcionar ao aluno o estudo sobre os elementos do ensino (temas clássicos da Didática) e sobre o processo ensino aprendizagem, o aluno poderá acabar ficando sem essas importantes reflexões.

Essa tendência em trabalhar com novas temáticas originadas nos debates educacionais, curriculares e no âmbito dos cursos de formação de professores foi considerada nesta pesquisa como um dos elementos do código disciplinar da disciplina de Didática.

A presença de novas temáticas, encontradas nos manuais de Didática, demonstra o desafio que a disciplina tem enfrentado no que se refere à necessidade de ampliação das questões tratadas, de diversificação e pluralidade de temáticas que podem concorrer para uma perda de seu foco, consolidado ao longo das três últimas décadas em torno do processo de ensino.

A partir da análise dos manuais, defende-se que as transformações ocorridas na Didática enquanto campo científico - e que produziram transformações também nos manuais didáticos - resultaram em uma focalização mais clara do objeto da disciplina em torno do ensino e dos elementos da ação docente, ressignificando as finalidades da disciplina em torno de três eixos:

- formar professores a partir da reflexão e da orientação das ações para o ensino em perspectiva multidimensional;

- construir espaços de transformação do trabalho docente pela valorização da reflexão e da investigação;

- a compreensão ampliada dos elementos constitutivos do ensino, que abre espaço para novos temas originados das demandas sociais em cada período histórico.

O código disciplinar da Didática, neste momento, evidencia uma reaproximação dos conteúdos e finalidades da disciplina com o espaço da sala de aula e com os procedimentos de ensino, sem defender uma perspectiva meramente tecnicista e sem desconhecer suas outras dimensões.

Concluindo, defende-se que a disciplina de Didática deve apresentar ao professor em formação conteúdos e temáticas que o coloquem em contato com as questões relacionadas ao ensino e ao trabalho docente, possibilitando a pesquisa e o debate sobre o que ocorre na sala de aula, levando-o a compreender as concepções e práticas que estão presentes nas escolas, bem como a construir possibilidades de transformação dessas concepções e práticas. 


\section{autêntica}

DOI https://doi.org/10.31639/rbpfp.v\%vi\%i.189

Defende-se que apesar da necessidade da inserção de novas temáticas e das relações de complementaridade entre a Didática e outros campos de conhecimento é importante que sejam trabalhados os conhecimentos didáticos indispensáveis na formação do futuro docente. Isso, pois, "quem ensina precisa estar sempre aprendendo e reaprendendo quem é o aluno a quem precisa ensinar. Precisa estar sempre refletindo sobre sua sala de aula e sua prática" (MOREIRA; MELGAÇO DA SILVA JÚNIOR, 2016, p.52).

Propõe-se que não deixe de lado o que se constitui como fundamental e objeto da Didática, que é colocar o professor em formação em contato com as questões de ensino, incluindo a compreensão e a reflexão sobre questões específicas desse processo e do trabalho docente, dando a ele instrumentos para o seu trabalho em sala de aula. 


\section{autêntica}

DOI https://doi.org/10.31639/rbpfp.v\%vi\%i.189

\section{REFERENCIAS}

ANDRÉ, Marli.; OLIVEIRA, Maria Rita N. S. (Org.). Alternativas do Ensino de Didática. São Paulo: Papirus, 1997.

Marli E. Tendências no ensino de Didática no Brasil. In: PIMENTA, Selma Garrido (org.) Didática e formação de professores: percursos e perspectivas no Brasil e em Portugal. $3^{\mathrm{a}}$ ed. São Paulo: Cortez, 2000. p. $191-204$

Marli E. Tendências da pesquisa e do conhecimento didático no início dos anos 2000. In: ENCONTRO NACIONAL DE DIDÁTICA E PRÁTICA DE ENSINO. Trajetórias e processos de ensinar e aprender: Didática e formação de professores. Anais XV Endipe. Rio Grande do Sul: EDIPUCRS, 2008. p. 487-499.

Marli E; CRUZ, Gisele B. A produção do conhecimento didático na RBEP (1998-2010). Revista brasileira de estudos pedagógicos, v. 93, p. 443-462, 2012.

Marli E, CRUZ, Gisele. B. A produção do conhecimento didático e a formação de professores no Brasil. In: OLIVEIRA, Maria Rita, PACHECO, José Augusto (Org.). Currículo, didática e formação de professores. $1^{a}$ ed. - Campinas, SP: Papirus, 2013. (Série Prática Pedagógica).

BARDIN, Laurence. Análise de Conteúdo. Lisboa, Portugal; Edições 70, LDA, 2009

CANDAU, Vera M. A Didática em questão. Rio de Janeiro: Vozes, 1983.

Vera. M. \& LEITE, Miriam S. A Didática na perspectiva multi/intercultural em ação: construindo uma proposta. Cadernos de Pesquisa, v. 37, n 132, p. 731-758, set./dez. 2007.

CASTRO, Amélia. D. de. A Trajetória Histórica da Didática. Série Ideias, n 11. São Paulo: FDE, 1991. p. 15-25. Disponível em <http://www.crmariocovas.sp. gov.br/pdf/ideias_11_p015-025_c.pdf>. Acesso em: 08 maio 2013.

Amélia. D. de; CARVALHO, Ana. Maria P. (Org.) Ensinar a ensinar: Didática para a Escola Fundamental e Média. São Paulo: Pioneira Thomson Learning, 2001.

CHERVEL, André. História das disciplinas escolares: reflexões sobre um campo de pesquisa. Revista Teoria e Educação, Porto Alegre, n. 2. p. 177-229,1990.

CRUZ, Gisele. B. da; ANDRÉ, Marli. E. Ensino de didática: um estudo sobre concepções e práticas de professores formadores. Educ. Rev., Belo Horizonte, v. 30, n. 4, p. 181-203, Dec. 2014

CUESTA FERNANDEZ, Raimundo. Clío en las aulas: la enseñanza de la historia en España entre reformas, ilusiones y rutinas. Madrid: Akal, 1998.

FARIAS, Isabel M. S. de. et al. Didática e Docência: aprendendo a profissão. Brasília: Liber Livro, 2009.

FRANCO. Maria Laura P. B. Análise de Conteúdo. Brasília, 2ª edição; Líber Livros Editora, 2005 


\section{autêntica}

DOI https://doi.org/10.31639/rbpfp.v\%vi\%i.189

FRANCO, Maria Amélia. S; FUSARI, José Carlos. Apresentação. In: FRANCO, M. A. S.; PIMENTA, S. G. (Org). Didática: embates contemporâneos. São Paulo: Edições Loyola, 2010.

. Maria Amélia S. \& GUARNIERI, Maria Regina. Disciplina de Didática: Um Estudo Exploratório a Partir dos Planos de Ensino. Revista Eletrônica Pesquiseduca, v. 3, n.5, jan.- jun. CATÓLICA UNISANTOS: 2011.

GARCIA, Tania. M. F B. Treinando habilidades para o ensino: perspectivas da Didática no início da década de 1970. In: Encuentro Internacional de Historia de la Educación "Entre la memoria y el olvido. Culturas, comunidades, saberes, 10, 2006. Anais... Guanajuato, México, 2006, p. 1-10, 2006 (CDROM).

GATTI, Bernadete. A; NUNES, Marina M. R. (Org.). Formação de professores para o ensino fundamental: estudo de currículos das licenciaturas em Pedagogia, Língua Português, Matemática e Ciências Biológicas. Textos FCC, São Paulo, v. 29, 2009. 155p.

HAYDT, Régina Célia C. Curso de Didática Geral. São Paulo, Ática. 1996.

LACANALLO, Luciana F et al. Métodos de ensino e de aprendizagem: uma análise histórica e educacional do trabalho didático. Anais....VII Jornada do HISTEDBR. O trabalho didático na história da educação. Campo Grande, 17 a 19 de setembro de 2007.

LIBANEO, José Carlos. Didática. São Paulo: Cortez, 1992.

José Carlos. Didática: velhos e novos temas. Goiânia. Edição do Autor. 2002

José Carlos. O campo teórico e profissional da Didática hoje: entre Ítaca e o canto das sereias.

In: Encontro Nacional de Didática e Prática de Ensino. Trajetórias e processos de ensinar e aprender: Didática e formação de professores. XV ENDIPE. Rio Grande do Sul: EDIPUCRS, 2008. [234-251]

José Carlos. O ensino da Didática, das metodologias específicas e dos conteúdos específicos do ensino fundamental nos currículos dos cursos de Pedagogia. In: Revista Brasileira de Estudos Pedagógicos - RBEP. Brasília, v. 91, n²29, p. 562-583, 2010.

MAIA, Helenice; MONTEIRO, Gabriela. C. dos S. A Didática na Formação Docente do Curso de Licenciatura em Pedagogia. Anais do EDUCERE. 2011.

MARIN, Alda J. Didática e currículo: conceitos, pesquisa e necessidade de avanço. In: Colóquio Luso-Brasileiro sobre Questões Curriculares, 7. , Colóquio Sobre Questões Curriculares, 4, 2008, Florianópolis. Anais... Florianópolis: [s.n.], 2008.

; Alda J. PENNA, Marieta G. O; RODRIGUES, A. C. C. A Didática e a Formação De Professores. Revista Diálogo Educacional. PUC/PR. Curitiba, V. 12, n. 35, p. 51-77, jan, abril 2012.

MARTINS, José do Prado. Didática Geral: fundamentos, planejamentos, metodologia, avaliação. São Paulo, Atlas, 1985

MARTINS, Pura Lúcia. Didática teórica/Didática prática: para além do confronto. 9. ed. São Paulo: Loyola, 1989. 


\section{autêntica}

DOI https://doi.org/10.31639/rbpfp.v\%vi\%i.189

Pura Lúcia. O, O campo da Didática: expressão das contradições da prática. In: EGGERT, E. et al. (Org.). Trajetórias e processos de ensinar e aprender: Didática e formação de professores. Porto Alegre: EDIPUCRS, 2008, p. 585-601.

Pura Lúcia. O. ROMANOWSKI, Joana P. A Didática na formação pedagógica de professores nas novas propostas para os cursos de licenciatura. In: Convergências e tensões no campo da formação e do trabalho docente / organização de Ângela Imaculada Loureiro de Freitas Dalben ... [et al]. - Belo Horizonte: Autêntica. XV ENDIPE - Encontro Nacional de Didática e Prática de Ensino realizado na UFMG. No período de 20 a 23 de abril de 2010.

MELLO, Josefina C. D. de. História da disciplina Didática geral em uma escola de formação de professores: (re) apropriação de discursos acadêmicos nos anos de 1980 e 1990. Dissertação (Mestrado em Educação) - Faculdade de Educação, Universidade Federal do Rio de Janeiro, Setembro, 2002.

MOREIRA, Antônio F. B; MELGAÇO DA SILVA JÚNIOR, PAULO. Revista Tempos e Espaços em Educação, São Cristóvão, Sergipe, Brasil, v. 9, n. 18, p. 45-54, jan./abr. 2016.

PACHECO, José Augusto; OLIVEIRA, Maria Rita. Os campos do currículo e da didática. In:

OLIVEIRA, M. R.; PACHECO, J. A. (Org.). Currículo, didática e formação de professores. Campinas: Papirus, 2013. p. 21-44

PILETTI, Claudino. Didática geral. Rio de Janeiro: Zahar, 1982.

PIMENTA, Selma. G. Epistemologia da prática ressignificando a Didática. Anais do XIV ENDIPE Encontro nacional de Didática e Prática de Ensino, 2008, Porto Alegre. Trajetórias e processos de ensinar e aprender: Didática e formação de professores. Porto Alegre: CD Room, 2008. v. 1. p. 602-625.

Selma. G. FRANCO, Maria Amélia S. Didática: Embates Contemporâneos. Editora: Loyola: 2010.

SILVA, Vivian. B. da. Os livros das normalistas: os manuais pedagógicos na história da formação dos professores no Brasil (1930-1971), Revista QUAESTIO, Sorocaba, São Paulo, v. 10, n. 1/2, p. 115-132, maio/nov. 2008.

TARDIF, Maurice. Saberes docentes e formação profissional. 4ª Ed. Rio de Janeiro: Vozes, 2002.

TOSI, Maria R. Didática geral: um olhar para o futuro. 1. ed. Campinas, SP: Editora Alínea. 1996

VEIGA, IIma. P. A. Lições de didática: Campinas, SP: Papirus, 2006

VEIGA, IIma. P. A. et al. Por dentro da Didática: um retrato de três Pesquisas. In: Anais do XV ENDIPE. Belo Horizonte: Autêntica, 2010.

VIEIRA, Débora Cristina. de O.; MARTINS, Pura Lucia. O. As Disciplinas de Didática nos Cursos De Licenciaturas. IX congresso Nacional de Educação EDUCERE, PUCPR, 2009. 


\section{autêntica}

DOI https://doi.org/10.31639/rbpfp.v\%vi\%i.189

Léia de Cássia Fernandes Hegeto

Universidade Federal do Paraná

Rua Maranhão, 23, sobrado 79,

Bairro: Boneca do Iguaçu,

Cidade: São José dos Pinhais

Cep: 8304060

e-mail: leiahegeto@hotmail.com 
